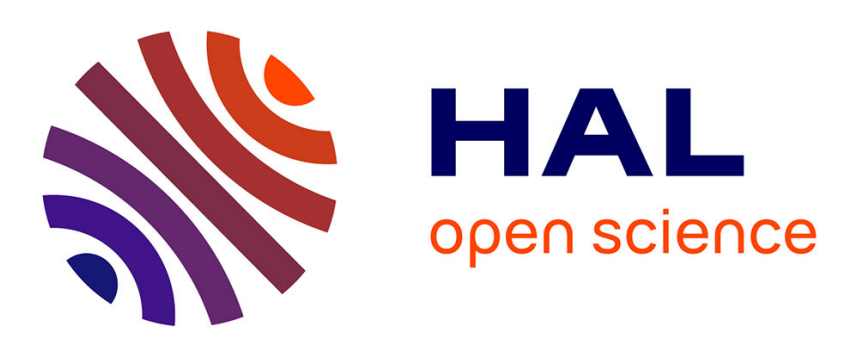

\title{
Diagnosing Mixing Properties in Model Simulations for CH4 in the Stratosphere
}

\author{
Zhiting Wang, Nils Hase, Justus Notholt, Bart Dils, Marielle Saunois, \\ Thorsten Warneke, Wenshou Tian
}

\section{> To cite this version:}

Zhiting Wang, Nils Hase, Justus Notholt, Bart Dils, Marielle Saunois, et al.. Diagnosing Mixing Properties in Model Simulations for CH4 in the Stratosphere. Journal of Geophysical Research: Atmospheres, 2020, 125 (15), 10.1029/2020JD032524 . hal-02938401

\section{HAL Id: hal-02938401 https://hal.science/hal-02938401}

Submitted on 14 Jun 2021

HAL is a multi-disciplinary open access archive for the deposit and dissemination of scientific research documents, whether they are published or not. The documents may come from teaching and research institutions in France or abroad, or from public or private research centers.
L'archive ouverte pluridisciplinaire HAL, est destinée au dépôt et à la diffusion de documents scientifiques de niveau recherche, publiés ou non, émanant des établissements d'enseignement et de recherche français ou étrangers, des laboratoires publics ou privés. 


\section{JGR Atmospheres}

\section{RESEARCH ARTICLE 10.1029/2020JD032524 \\ Diagnosing Mixing Properties in Model Simulations for $\mathrm{CH}_{4}$ in the Stratosphere}

Key Point:

- A significant improvement in the modeled isentropic mixing in the stratosphere is obtained if the vertical resolution is improved there

Correspondence to:

Z. Wang,

wangzt@lzu.edu.cn

Citation:

Wang, Z., Hase, N., Notholt, J., Dils, B., Saunois, M., Warneke, T., \& Tian, W. (2020). Diagnosing mixing properties in model simulations for $\mathrm{CH}_{4}$ in the stratosphere. Journal of Geophysical Research: Atmospheres, 125, e2020JD032524. Accepted Author Manuscript. https://doi.org/10.1029/ 2020JD032524

Received 16 MAR 2020 Accepted 3 JUL 2020

Accepted article online 7 JUL 2020
(C)2020. American Geophysical Union. All Rights Reserved.

\author{
Zhiting Wang ${ }^{1,2}$ (D) Nils Hase ${ }^{2}$ (D) Justus Notholt ${ }^{2}$ (D), Bart Dils ${ }^{3}$, Marielle Saunois ${ }^{4}$ (D), \\ Thorsten Warneke ${ }^{2}$ iD, and Wenshou $\operatorname{Tian}^{1}$ iD \\ ${ }^{1}$ College of Atmospheric Science, Lanzhou University, Lanzhou, China, ${ }^{2}$ Institute of Environmental Physics, University of \\ Bremen, Bremen, Germany, ${ }^{3}$ Belgian Institute for Space Aeronomy, BIRA-IASB, Brussels, Belgium, ${ }^{4}$ Laboratoire des \\ Sciences du Climat et de l'Environnement, LSCE-IPSL (CEA-CNRS-UVSQ), Université Paris-Saclay, Gif-sur-Yvette, \\ France
}

\begin{abstract}
Isentropic mixing properties in the stratosphere modeled by the forward calculation of an inverse model (TM5-4DVAR) are evaluated against Michelson Interferometer for Passive Atmospheric Sounding (MIPAS) and Microwave Limb Sounder (MLS) observations. The isentropic mixing processes are separated into large-scale stirring described by the "equivalent length" and small-scale diffusion described by the diffusivity. Compared to the measurements, we find that the modeled stirring is not strong enough and that the small-scale diffusivity is too large. TM5-4DVAR produces excessive mixing-induced poleward flux for stratospheric $\mathrm{CH}_{4}$. The flux convergence presents negative biases in the tropics and positive biases in the polar regions. The biases cannot be reduced by improving the horizontal resolution only. Modeled isentropic mixing depends on the horizontal as well as the vertical resolution of the model. An increase in vertical resolution reduces numerical diffusion of the model in the vertical. The decreased vertical diffusion leads to reduction in the modeled isentropic diffusivity. Biases in modeled total column-averaged mixing ratios of $\mathrm{CH}_{4}$ are significant for both models with a coarse vertical resolution of $4^{\circ} \times 6^{\circ} \times 25$ (and $2^{\circ} \times 3^{\circ} \times 25,1^{\circ} \times 1^{\circ} \times 25$ ) and an improved one of $1^{\circ} \times 1^{\circ} \times 40$. They are estimated to be 7-14 and 3-7 ppb in the winter extratropics under the assumption that isentropic mixing is dominant over vertical transport on a time scale of 3 days. Correspondingly, resulted biases in inverted $\mathrm{CH}_{4}$ surface emissions are estimated to be 0.5-1 and $0.2-0.5 \mathrm{mg} / \mathrm{m}^{2} / \mathrm{hr}$, respectively, in the extratropics.
\end{abstract}

\section{Introduction}

Inverse modeling is widely used to infer methane $\left(\mathrm{CH}_{4}\right)$ emissions from measured concentrations. The most frequently used measurements include $\mathrm{CH}_{4}$ mixing ratios at the surface, and total column-averaged mixing ratios from satellite-based sensors (e.g., SCIAMACHY described in Bovensmann et al., 1999, and GOSAT in Kuze et al., 2016). Compared to in situ surface measurements, satellite-based instruments provide valuable information due to their better spatial coverage. This larger coverage is particularly important for tropical regions where in situ measurements are sparse, such as in South America (Pison et al., 2013). However, inaccuracies in the models prevent correct extraction of the information on the sources by inverse models. For example, retrieved surface emissions change when applying different physical parameterization or different vertical resolutions (Locatelli et al., 2015). Specially, model errors in the stratosphere could be aliased into wrong tropospheric emissions when the inverse models use total column-averaged mixing ratio measurements. An approach to reduce the impact of model deficiencies in the stratosphere is to use satellites measurements that have small sensitivities for the stratospheric $\mathrm{CH}_{4}$. For example, Payne et al. (2009) describe a method that extracts the tropospheric $\mathrm{CH}_{4}$ concentrations with peak sensitivities around $500 \mathrm{hPa}$ from the Tropospheric Emission Spectrometer (TES) measurements. Crevoisier et al. (2013) and Xiong et al. (2013) retrieve a middle-to-upper tropospheric $\mathrm{CH}_{4}$ concentration from the Infrared Atmospheric Sounding Interferometer (IASI) (where the most sensitive layer is between 100-600 hPa in the tropics and 200-750 hPa in the extratropics). Worden et al. (2015) present lower tropospheric $\mathrm{CH}_{4}$ retrieved by using a combination of TES and GOSAT sensors with an estimated accuracy of 10-30 ppb for monthly averages. However, all these $\mathrm{CH}_{4}$ products still have a stratospheric contribution even if their highest sensitivities are in the troposphere. 
$\mathrm{CH}_{4}$ is emitted at the surface and transported into the stratosphere mainly in the tropics. In the stratosphere, $\mathrm{CH}_{4}$ is distributed globally by the residual circulation and isentropic mixing processes induced by wave breaking events, for example, planetary wave breaking (Mcintyre \& Palmer, 1983). Chemical oxidation destroys $\mathrm{CH}_{4}$ mostly in the upper stratosphere and results in a strong decline of $\mathrm{CH}_{4}$ concentrations with altitudes above the tropopause. However, in the stratosphere transport barriers exist, such as the subtropical barrier (Chen et al., 1994a; Neu, 2003; Trepte \& Hitchman, 1992) and the polar vortex barrier (Chen et al., 1994b; Steinhorst et al., 2005). Isentropic mixing processes contribute to (1) horizontally uniform tracer distributions in the surf zone, which is a region strongly stirred by planetary wave breaking in the winter stratosphere as defined by Mcintyre and Palmer (1983), and (2) strong gradients of tracer concentrations at ends of the surf zone.

In the stratosphere the transport of chemical tracers across the subtropical and polar barrier occurs as filamentary structures induced by wave breaking events (Chen, 1994; Chen et al., 1994b; Kalicinsky et al., 2013; Randel et al., 1993). However, usually Eulerian models do not represent filament structures as good as Lagrangian models (e.g., Khosrawi et al., 2005) and thus could have difficulties in capturing transport across barriers. For example, CTMs (Chemistry Transport Model) using a Lagrangian transport scheme give much better performances in representing large $\mathrm{CH}_{4}$ gradients across these transport barriers in the stratosphere compared to the Eulerian based models (Hoppe et al., 2014; Stenke et al., 2009). Model deficiencies in the stratosphere need to be understood to improve their performance and to obtain an estimate to what degree the $\mathrm{CH}_{4}$ emissions from inversion studies can be trusted when total column-averaged mixing ratio measurements are used.

In this work the forward mode of the inverse model TM5-4DVAR, a model frequently used for inversions of $\mathrm{CH}_{4}$ emissions, is evaluated in the stratosphere. Precisely, the mixing properties of the model in the stratosphere are analyzed in comparison to satellite observations. The analysis is based on the modified Lagrangian-mean (MLM) approach (Allen \& Nakamura, 2001; Haynes \& Shuckburgh, 2000; Nakamura, 1996; Nakamura \& Ma, 1997). Further, the model biases in the stratosphere are estimated. The influence of these model biases on retrieved surface emissions is briefly discussed.

\section{Data and Method}

\subsection{Model and Measurements}

TM5-4DVAR is a four-dimensional data assimilation system for inverse modeling of atmospheric methane emissions (Bergamaschi et al., 2013, 2015; Meirink et al., 2008). The system is based on the TM5 atmospheric transport model (Krol et al., 2005). The model is driven by ERA-Interim reanalysis data that has a resolution of $1^{\circ} \times 1^{\circ} \times 60$ (latitudinal and longitudinal resolution, and number of vertical levels). In this study, we only use the forward mode of the model to simulate spatiotemporal $\mathrm{CH}_{4}$ fields to prescribed surface emissions. The surface emissions of $\mathrm{CH}_{4}$ are taken from the MACC (Monitoring Atmospheric Composition and Climate) data set. The model resolutions under testing are $4^{\circ} \times 6^{\circ} \times 25,2^{\circ} \times 3^{\circ} \times 25,1^{\circ} \times 1^{\circ} \times 25$, $1^{\circ} \times 1^{\circ} \times 40$ and $1^{\circ} \times 1^{\circ} \times 63$. Pressures at interface of the model levels are tabulated in Table 1 . TM5-4DVAR automatically maps the ERA-Interim meteorology data to the defined model resolution.

The resolution $4^{\circ} \times 6^{\circ} \times 25$ is a standard setup in previous studies for investigating the surface emissions of $\mathrm{CH}_{4}$ (Bergamaschi et al., 2013, 2015). Compared to the 25 vertical layers setup, the additional layers in 40 vertical layers setup are all located above $165 \mathrm{hPa}$. The setup with 40 vertical layers has the same vertical layers as the original ERA-Interim data sets between 165 and $1.8 \mathrm{hPa}$. The 63 vertical layers setup has double vertical resolution in that pressure range. The parameterized chemical sinks of $\mathrm{CH}_{4}$ include reactions with tropospheric hydroxyl (OH) radicals (Spivakovsky et al., 2000) and stratospheric radicals from ECHAM5 (Bergamaschi et al., 2013; Joeckel et al., 2006). The concentration fields of the radicals are prescribed monthly with no interannual changes.

The measured stratospheric $\mathrm{CH}_{4}$ profiles during 2009-2011 are taken from MIPAS (Michelson Interferometer for Passive Atmospheric Sounding) instrument (Fischer et al., 2008). MIPAS samples the middle and upper atmosphere along polar orbits with a swath width of $3 \times 30 \mathrm{~km}$. There are 14.3 orbits per day and about 73 limb scans along one orbit. The primary geophysical parameters of interest are vertical 
Table 1

Pressures at the Interface of 25, 40, and 63 Model Levels Assuming a Surface Pressure of 1,013.25 hPa

\begin{tabular}{lrc}
\hline$p(\mathrm{hPa}) / 63$ & $p(\mathrm{hPa}) / 40$ & $p(\mathrm{hPa}) / 25$ \\
\hline 0.00 & 0.00 & 0.00 \\
0.96 & 0.96 & 0.96 \\
1.81 & 1.81 & \\
2.08 & & \\
2.35 & 2.35 & 2.98 \\
2.67 & & \\
2.98 & 2.98 & \\
3.36 & & \\
3.74 & 3.74 & \\
4.19 & & \\
4.65 & 4.65 & \\
5.20 & & \\
5.76 & 5.76 & \\
6.44 & & \\
7.13 & 7.13 & \\
7.98 & & \\
8.84 & 8.84 & \\
9.89 & & \\
10.95 & 10.95 & \\
12.26 & & \\
13.56 & 13.56 & \\
15.19 & 16.81 & \\
16.81 & &
\end{tabular}

18.81

20.82

23.31

25.80

28.88

31.96

35.78

39.60

44.34

49.07

54.62

60.18

66.62

73.07

80.40

87.73

95.98

104.23

113.42

122.61

132.76

142.90

153.99

165.09

177.11

215.02

272.04

336.01

406.08

480.72

557.88

635.18

710.12

780.17

843.07

896.90
20.82

25.80

31.96

39.60

49.07

60.18

73.07

87.73

104.23

122.61

142.90

165.09

215.02

272.04

336.01

406.08

480.72

557.88

635.18

710.12

780.17

843.07

896.90 profiles of atmospheric pressure, temperatures, and volume mixing ratios of about 25 trace constituents. The product used here is the operational V7 data processed by the European Space Agency (ESA).

For comparison of the model with the measurements, modeled 3-D fields are sampled at each measurement location and time through spatiotemporal interpolations.

\subsection{Estimation of Trace Gas Fields From Point Observations}

The upcoming analysis requires a global spatiotemporal trace gas concentration field along isentropic surfaces. We construct such a field by fitting a truncated spherical harmonics expansion to the observed/simulated concentrations at the measurement locations using a weighted least squares approach. Spherical harmonics are a set of Fourier-like basis functions defined on a spherical surface. The series of spherical harmonics is truncated with the R20 (rhomboidal) truncation (e.g., Daley \& Bourassa, 1978), which selects the large-scale components of the expansion. The estimated $\mathrm{CH}_{4}$ field is a globally defined approximation on the isentropic surface with a spatial resolution of about $3.6^{\circ} \times 6^{\circ}$.

This spectral approximation is performed for both the model and the measurement data. One approximation is estimated for each 10 days period at each isentrope. The MIPAS data are weighted according to the measurement uncertainties. The weights for the model are unitary. The 10 days period is required to accumulate sufficient MIPAS observations for a stable estimate of the spherical approximation at the chosen resolution, R20. Actually, the accumulated MIPAS data of 7 days suffices to stably estimate the R20 truncated approximation. However, to validate the diagonostic method with data from the MLS (Microwave Limb Sounder; see section 3.1) a longer aggregation period is required due to the larger measurement noise of MLS.

For the following analysis the concentration field is sampled on isentropic surfaces on a $1^{\circ} \times 1^{\circ}$ grid. The spectral approximation of the model data is solely based on the data at the measurement locations of the satellite instead of using the full model output. This approach allows a direct comparison between the model data and the observations. At the same time certain features of the modeled $\mathrm{CH}_{4}$ field could be lost. A comparison of the spectral approximations from the full model simulation and from the subset of observations shows that both approaches lead to virtually identical results. This result implies that our approach to compare model data and measurements is reasonable.

\subsection{Theory and Analysis Method}

The meridional mixing in the stratosphere is investigated by analyzing the mixing ratio of long-lived trace gases along isentropic surfaces. The meridional transport in the stratosphere is characterized by regions of strong mixing separated by transport barriers. Zonal averaging approaches are less suited for the analysis of transport barriers, because exact positions of transport barriers are permanently disturbed by atmospheric waves. A more adequate approach is the modified Lagrangian-mean framework. 
Table 1

Continued

\begin{tabular}{lrr}
\hline$p(\mathrm{hPa}) / 63$ & $p(\mathrm{hPa}) / 40$ & $p(\mathrm{hPa}) / 25$ \\
\hline 940.32 & 940.32 & 940.32 \\
972.75 & 972.75 & 972.75 \\
994.50 & 994.50 & 994.50 \\
$1,007.02$ & $1,007.02$ & $1,007.02$ \\
$1,013.00$ & $1,013.00$ & $1,013.00$ \\
\hline
\end{tabular}

Consider a two-dimensional distribution of a trace gas mixing ratio $q=q(x, y, t)$. The mixing ratio evolves according to the advection-diffusion equation, that is (assuming constant air density),

$$
\frac{\partial q}{\partial t}+\nabla \cdot(\vec{v} q-k \nabla q)=s
$$

where $\vec{v} q$ is the adective flux and $-k \nabla q$ is the diffusive flux with constant diffusion coefficient and $s$ is term describing sources and sinks.

The modified Lagrangian-mean approach observes the physical system in a different variable. Following Nakamura (1996), the areal integral of a function $f$ over the area enclosed by the contour line of some trace gas mixing ratio $q$ by

$$
\langle f\rangle_{q}=\int_{q^{\prime}(x, y) \leq q} f d s .
$$

Note that the area enclosed by this contour line is thus given by $(q)=\langle 1\rangle_{q}$. In this way $A(q)$ is a function that maps the mixing ratio $q$ to the area enclosed by the contour $q$. Generally, the inverse relationship $q=q(A)$ can be established as well. A snapshot of the atmospheric mixing ratio $q$ and the corresponding function $q(A)$ are illustrated in Figure 1. In the absence of diffusion and sources/sinks the function $q(A)$ is not changed by advection. Advection can deform or even split the contours of the trace gas field but it does not change the function $q(A)$. This is due to the fact the advection conserves the mixing ratio and the areal coordinate $A$ is of Lagrangian type; that is, it follows the flow of the atmosphere if the wind is divergence-free and hence area preserving. These conditions nearly apply to the stratosphere. The system observed on the areal coordinate is only changed by nonconservative processes such as diffusion and sources/sinks.

The advection-diffusion equation expressed with respect to $A$ has the form (cp. Nakamura, 1996)

$$
\frac{\partial q}{\partial t}(A, t)=\frac{\partial}{\partial A}\left(k L_{e}^{2}(A, t) \frac{\partial q}{\partial A}(A, t)\right)+\widehat{s}
$$

where $\widehat{s}$ is source/sink averaged along the contour line and $L_{e}(A, t)$ is called equivalent length given by
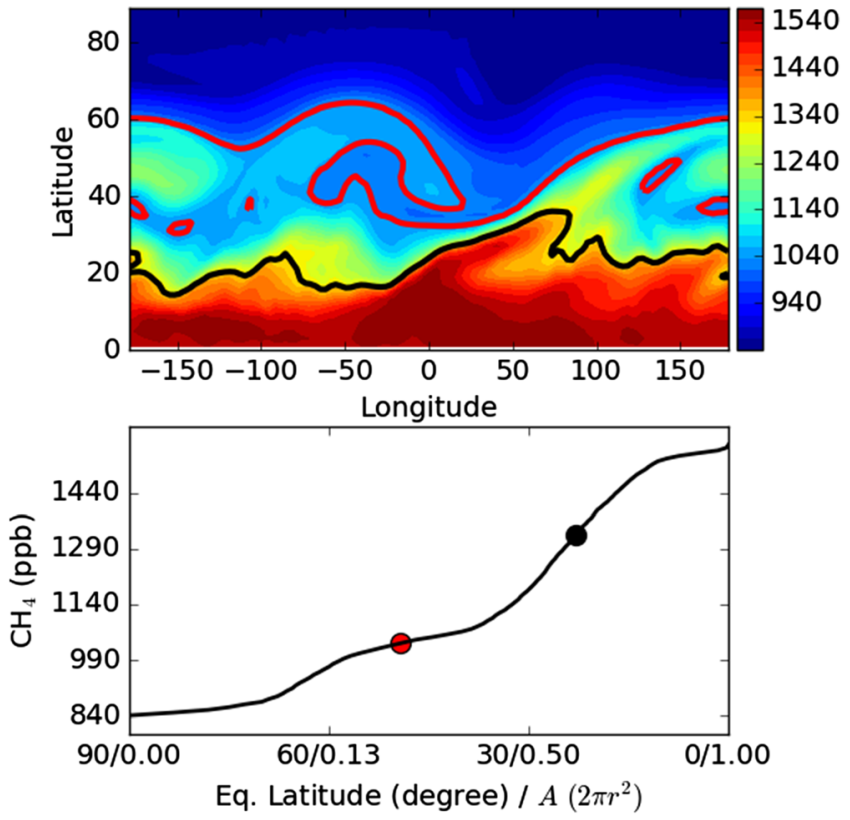

Figure 1. Snapshot of the Northern Hemispheric $\mathrm{CH}_{4}$ distribution on an isentropic surface (top). The same distribution observed in the areal variable $A$ and in equivalent latitude (bottom). The marked points correspond to the highlighted contours in the upper panel.

$$
L_{e}^{2}(A, t)=\frac{\partial\left\langle|\nabla q|^{2}\right\rangle_{q(A)} / \partial A}{(\partial q / \partial A)^{2}} .
$$

In Equation 2, large values of equivalent length increase the diffusive flux and eventually lead to flat gradients. Small values act as a barrier and gradients can form (cp. Figure 1). The equivalent length is approximately the length of the contour line and proportional to the gradient of the mixing ratio across the contour. Atmospheric wave disturbances can enhance $L_{e}$ through enlarging the length and strengthening the gradients. This action of wave disturbances is referred to as stirring (Haynes, 2004). So equivalent length acts as an indicator of the strength of stirring.

For spherical surfaces it can be convenient to express the areal coordinate $A$ in terms of equivalent latitude $\phi_{e}$. The corresponding equivalent latitude to the area $A$ is the latitudinal circle centered at the pole whose enclosed area is $A$, that is, $\phi_{e}=\arcsin \left(1-A / 2 \pi r^{2}\right)$, where $r$ is the radius of the sphere. In the spherical coordinate the MLM formalism has the form (cp. Nakamura \& Ma, 1997)

$$
\frac{\partial q\left(\phi_{e}, \theta, t\right)}{\partial t}=\frac{1}{\cos \phi_{e}} \frac{\partial}{r \partial \phi_{e}}\left(\cos \phi_{e} \frac{k_{h} L_{e}^{2}}{\left(2 \pi r \cos \phi_{e}\right)^{2}} \frac{\partial q}{r \partial \phi_{e}}\right)+\text { others }
$$

where $k_{h}$ is the small-scale isentropic diffusion coefficient. Equivalent length $L_{e}$ represents the strength of stirring. Both coefficients together are also referred to as the effective diffusivity $k_{\text {eff }}=$ 
$k_{h} L_{e}^{2} / L_{0}^{2}$, where $L_{0}=2 \pi r \cos \phi_{e}$ is the length of the circle on the spherical surface at latitude $\phi_{e}$. In Equation 3 the first term on the right-hand side describes mixing-induced flux convergence of the trace gas and is evaluated in this study. The "others" term includes contributions by diabatic motion and sources/sinks and is not concerned.

It should be noted that large-scale stirring has different properties than small-scale diffusion. Two processes cannot compensate for each other even though they are described by the same term in the MLM theory. Large-scale distortions stretch tracer contours but do not smooth the tracer gradients. Small-scale diffusion degrades the tracer gradient during the transport by decreasing high tracer concentrations and increasing lower tracer concentrations. On the isentropes the small-scale diffusion transports tracers more isotropically and uniformly than the large-scale disturbances. For example, wave disturbances can take air masses near the polar vortex boundary to lower latitudes where the tracer concentrations are very different from the polar regions in just a few days. Such transport exchanges only small amounts of trace gas with latitudes passed by the air mass. This effect cannot be achieved by a diffusion process. The $L_{e}$ is tightly related to wave activities and enlarged by wave breaking events as will be shown in section 3 . At the same time, the small-scale diffusion decreases $L_{e}$ through smoothing tracer distribution.

A normalization as suggested in Nakamura and $\mathrm{Ma}$ (1997) is applied to the equivalent length, that is, $E_{e}=\ln$ $\left(L_{e}^{2} / L_{0}^{2}\right)$. In this study, the normalized equivalent length is used as a measure for the strength of stirring processes that are resolved by the R20 truncated approximation. Hereafter the $E_{e}$ is just referred to as $L_{e}$ for convenience. For $\mathrm{CH}_{4}$ with maximum mixing ratio in the tropical regions and generally decreasing values toward the poles we evaluate each hemisphere separately.

In order to quantify $\mathrm{CH}_{4}$ biases induced by mixing processes the small-scale isentropic diffusivity $k_{h}$ must be estimated. For the observational data $k_{h}$ includes contributions from eddy motions unresolved by R20 truncated approximation, turbulences and the molecular diffusion. The $k_{h}$ in the model data includes eddies resolved by the original model resolution but unresolved by R20 truncated approximation, parameterized subgrid mixing, and the numerical diffusion. Previous studies estimate the average diffusivity from the evolution of the globally averaged tracer variance (Abernathy et al., 2010; Allen \& Nakamura, 2001; Leibensperger \& Plumb, 2014; Marshall et al., 2006). When restricting the averaging to the stratospheric region between the isentropic layers 500 and $1200 \mathrm{~K}$, the spatially averaged variance equation for that region reads (see Appendix A for a detailed derivation)

$$
\begin{aligned}
\frac{1}{2} \frac{d \overline{q^{2}}}{d t}-\frac{1}{2} \int_{\theta} & =500 K \\
& \sigma \dot{\theta} q^{2} \frac{d s}{M}+\frac{1}{2} \int_{\theta=1200 K} \sigma \dot{\theta} q^{2} \frac{d s}{M}=-k_{\theta}\left(\frac{1}{2} \int_{\theta=500 \mathrm{~K}} \sigma \frac{\partial q^{2}}{\partial \theta} \frac{\mathrm{ds}}{M}-\frac{1}{2} \int_{\theta=1200 \mathrm{~K}} \sigma \frac{\partial q^{2}}{\partial \theta} \frac{\mathrm{ds}}{M}+\overline{\left(\frac{\partial q}{\partial \theta}\right)^{2}}\right) \\
& -k_{h} \overline{\left.\nabla_{h} q\right|^{2}}-\frac{\overline{q^{2}}}{\tau_{\text {chem }}} .
\end{aligned}
$$

In this equation $q$ is the trace gas mixing ratio, $\sigma=-g^{-1} \partial p / \partial \theta$ is the potential temperature coordinate density, $\dot{\theta}$ denotes the diabatic heating rate, $M$ is the air mass between the two isentropes, $\nabla_{h}$ denotes the components of the gradient operator within the isentropic surface, $k_{\ominus}$ is the small-scale diabatic diffusivity, and $\tau_{\text {chem }}$ is the averaged chemical lifetime of the trace gas in this region. The overbar represents the mass-weighted mean over the volume enclosed by the isentropic layers 500 and $1200 \mathrm{~K}$. The tracer variance equation lists the processes that change the mean variance of the tracer in the defined region. Advective and diffusive fluxes over the vertical boundaries can transport variance in and out of the region. Within the region the variance is reduced by horizontal and vertical diffusion as well as by chemical oxidation.

For the modeled $\mathrm{CH}_{4}$ the boundary conditions and chemical sinks are known and can be calculated explicitly. Then the tracer variance equation is of the form $f(t)=k_{\ominus} a(t)+k_{h} b(t)$. The coefficient of $k_{\ominus}$ has a much larger variation range than that of $k_{h}$. So first, $k_{\ominus}$ is estimated by linear regression of $k_{\ominus}$ and a constant $c$ in $f(t)=k_{\ominus} a(t)+c$. In a second step $k_{h}$ is estimated through linear regression against $b(t)$ with fixed $k_{\theta}$.

The estimation for the MIPAS data follows a different procedure. Time series of the retrieval have discontinuities due to changes in the gain of the detector for B-band of MIPAS. Evaluation of the time derivative of the averaged $\mathrm{CH}_{4}$ variance is interfered significantly. To reduce influences of the discontinuities, Equation 4 
is normalized through being divided by $\overline{q^{2}}$. The diffusivities are estimated from the difference of the normalized tracer variance equations for $\mathrm{CH}_{4}$ and $\mathrm{N}_{2} \mathrm{O}$. With $q_{1}=\overline{q_{\mathrm{CH}_{4}}^{2}}$ and $q_{2}=\overline{q_{N_{2} \mathrm{O}}^{2}}$ the difference equation include the time derivative of the variance in a form $\frac{d}{d t} \ln \left(\frac{q_{1}}{q_{2}}\right)$. Since both trace gases are retrieved from the B-band the fraction $q_{1} / q_{2}$ reduces the impact of the discontinuities significantly. The diffusivities can now be estimated using the above mentioned linear regression.

Diabatic heating rates $\dot{\theta}$ from two different reanalysis data sets, ERA-Interim and MERRA-2, are applied for the MIPAS data. It is revealed that the estimated isentropic and diabatic diffusivities are $\left(1.48 \times 10^{5} \mathrm{~m}^{2} / \mathrm{s}\right.$, $\left.0.0001 \mathrm{~K}^{2} / \mathrm{s}\right)$ when applying the ERA-Interim diabatic heating rates and $\left(2.17 \times 10^{5} \mathrm{~m}^{2} / \mathrm{s}, 0.0003 \mathrm{~K}^{2} / \mathrm{s}\right)$ when applying those of the MERRA-2. For the following analysis, the value $k_{h}=2.17 \times 10^{5} \mathrm{~m}^{2} / \mathrm{s}$ is used because they are closer to model results. In this way, we try to estimate lower limits in the models biases.

\section{Validation of the $L_{e}$ as a Measure for Stirring Strength}

\section{1. $L_{e}$ Magnitude Validation}

The $L_{e}$ is determined by the structure of the tracer contour for a specific moment. For inert tracers the tracer contours are in equilibrium with the flow and share similar geometries (Haynes \& Shuckburgh, 2000). Consequently, the $L_{e}$ derived from different inert tracers are the same. As long as the local lifetimes of tracers having a sink in the stratosphere are much longer than the timescale of isentropic mixing processes, $L_{e}$ derived from their distribution does not depend on the tracer and their destruction details. In the stratosphere both $\mathrm{CH}_{4}$ and $\mathrm{N}_{2} \mathrm{O}$ have long lifetimes and their contours at a certain altitude are mainly the results of air motions. So the $L_{e}$ derived from these tracers is a measure of stirring strength.

Figure 2 gives $L_{e}$ at 600 and $1100 \mathrm{~K}$ during the period 2009-2011 derived from $\mathrm{CH}_{4}$ and $\mathrm{N}_{2} \mathrm{O}$ mixing ratios measured by MIPAS and MLS. The MIPAS measured $\mathrm{CH}_{4}$ and $\mathrm{N}_{2} \mathrm{O}$ give very similar but not completely the same values for $L_{e}$. The reason is that the MIPAS measurement errors are different for the two gases. Validations of MIPAS retrievals with in situ measurements (Wetzel et al., 2016) show a positive bias for $\mathrm{CH}_{4}$ of $5 \%$ at $20 \mathrm{~km}(\approx 450 \mathrm{~K})$, which slowly increases to $10 \%$ at $40 \mathrm{~km}(\approx 1,300 \mathrm{~K})$ with about $5 \%$ standard deviation. For $\mathrm{N}_{2} \mathrm{O}$ the validation shows a positive bias of $15 \%$ between 20 and $32 \mathrm{~km}(\approx 900 \mathrm{~K})$. Above $32 \mathrm{~km}$ the bias of the $\mathrm{N}_{2} \mathrm{O}$ largely oscillates from $15 \%$ to $35 \%$ with standard deviation as large as $40 \%$. As $L_{e}$ depends on tracer contours the larger standard deviation of $40 \%$ in the validation of $\mathrm{N}_{2} \mathrm{O}$ retrievals indicates that the $L_{e}$ derived from MIPAS measured $\mathrm{N}_{2} \mathrm{O}$ mixing ratios suffer from more measurement noise. The $L_{e}$ distributions calculated with CLaMS model data as described in Pommrich et al. (2014) for 450-1500 K between $\mathrm{CH}_{4}$ and $\mathrm{N}_{2} \mathrm{O}$ are very similar (not shown). The MLS measured $\mathrm{N}_{2} \mathrm{O}$ gives similar $L_{e}$ as MIPAS but the differences between the instruments are larger than between $\mathrm{CH}_{4}$ and $\mathrm{N}_{2} \mathrm{O}$ from MIPAS data. Comparisons of MIPAS and MLS measured $\mathrm{N}_{2} \mathrm{O}$ with ACE-FTS measured $\mathrm{N}_{2} \mathrm{O}$ (Sheese et al., 2017) reveal that there is no mean bias between these instruments from 20 to $45 \mathrm{~km}$ but the MLS measurements present larger variabilities. The $1-\sigma$ relative differences are $10 \%$ at $20 \mathrm{~km}, 30 \%$ at $38 \mathrm{~km}$, and $60 \%$ at $45 \mathrm{~km}$ for MIPAS and $10 \%$ at $20 \mathrm{~km}$ and $100 \%$ at $38 \mathrm{~km}$ for MLS. The correlations between MIPAS and ACE-FTS stay near 0.9 in the range $20-45 \mathrm{~km}$, but those between MLS and ACE-FTS decrease with respect to altitudes above $30 \mathrm{~km}$ and become about 0.2 at $45 \mathrm{~km}$. In this study the $L_{e}$ derived from MIPAS $\mathrm{CH}_{4}$ are used to evaluate the modeled one since ACE-FTS measurements are usually considered to be highly accurate.

\subsection{Relation Between $L_{e}$ and Wave Activities}

In Eulerian (zonal) mean formulation zonal inhomogeneity in any quantity is referred as wave disturbance. Large wave disturbances usually are associated with wave breaking events in the extratropical stratosphere. Here, Eliassen-Palm flux (E-P flux) (Holton, 2004, p325) is calculated to reveal connection between the $L_{e}$ and wave activities. The quasi-geostrophic E-P flux is given by

$$
\vec{F}=\left(F_{\phi}, F_{z}\right)=r \cos \phi e^{-z / H}\left(\frac{-\overline{u^{\prime} v^{\prime}}, f \overline{v^{\prime} \theta^{\prime}}}{\bar{\theta}_{z}}\right),
$$

where $r$ is the Earth's radius and $z=H \ln \left(p_{0} / p\right)$ is the log-pressure coordinate and $H$ is a constant atmospheric scale height, $p_{o}$ and $p$ are constant reference pressure and atmospheric pressure, $u$ and $v$ are 

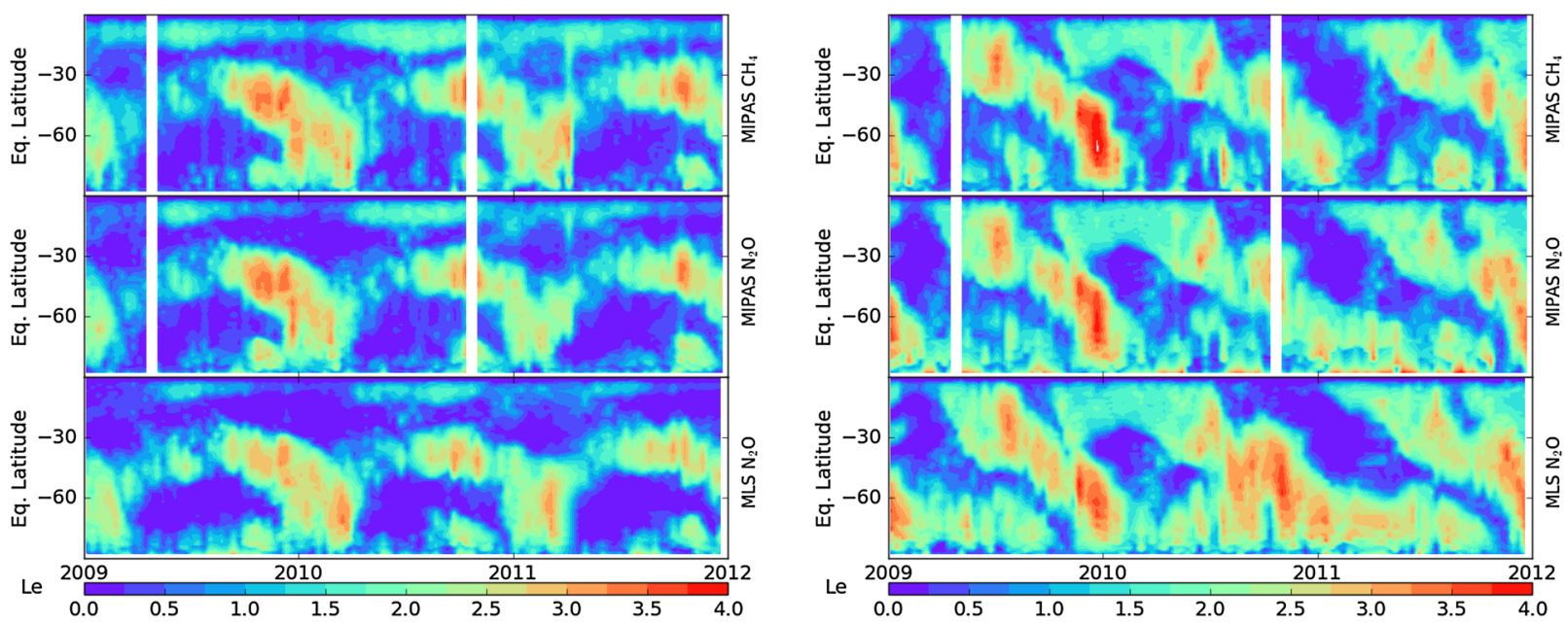

Figure 2. Temporal evolutions of $L_{e}$ at $600 \mathrm{~K}$ (left) and $1100 \mathrm{~K}$ (right) for the period 2009-2011 derived from $\mathrm{MIPAS}$ measured $\mathrm{CH}_{4}$ (top) and $\mathrm{N}_{2} \mathrm{O}$ (middle) mixing ratios, and from MLS measured $\mathrm{N}_{2} \mathrm{O}$ (lower) mixing ratios.

zonal and meridional disturbance velocities, $\phi$ is the latitude, and $f$ is the Coriolis parameter; the overbar means zonal average, and the primes indicate departure from zonal mean. The E-P flux vector represents the transport flux of wave activities.

The divergence of the E-P flux, $\nabla \cdot \vec{F} /\left(r \cos \phi e^{-z / H}\right)$, represents the acceleration of the zonally averaged zonal wind by wave disturbances and drives the residual circulation. According to the noninteraction theorem (Andrews et al., 1987; Edmon et al., 1980) for adiabatic conditions steady waves cannot change the zonal mean state of the atmosphere because the divergence of the E-P flux equals to 0. Only waves under development or dissipation produce nonzero E-P flux divergence, which occurs in wave breaking events. For quasi-geostrophic flow the divergence of the E-P flux equals to the meridional eddy flux of potential vorticity $\overline{v^{\prime} q^{\prime}}$ (Edmon, 1980; Palmer, 1982). When scaled by the meridional gradient of the zonal mean potential vorticity the eddy diffusivity in Eulerian mean formulation $K_{y y}=-\overline{v^{\prime} q^{\prime}} / \frac{\partial \bar{q}}{r \partial \phi}$ is produced. $K_{y y}$ is comparable to $L_{e}$ that composes the effective diffusivity in the tracer coordinate (Abalos et al., 2016).

Figure 3 compares MIPAS measured $L_{e}$ to the temporal evolutions of eddy diffusivity and the vertical component of the E-P flux (scaled by $\mathrm{H}$ ) calculated using ERA-Interim reanalysis data. The resolution of the reanalysis data is $2.5^{\circ} \times 3.75^{\circ} \times 60$. All quantities are averaged over the latitudes $30-50^{\circ} \mathrm{S}$. The similarity between their seasonal cycles indicates that $L_{e}$ is enlarged by wave disturbances. In order to know how much wave activities can be attributed to planetary scale waves the eddy diffusivity and E-P flux are calculated for both total disturbances and those with zonal wavenumber $\leq 4$. The results indicate that almost all wave activities result from planetary scale disturbances at the altitudes 450-1200 K (approximate 20-38 km).

In Abalos et al. (2016) the eddy diffusivity and $L_{e}$ for a passive tracer is compared in an altitude range 5-30 km and found high similarity between them. They also recognized a high similarity between eddy fluxes of the potential vorticity and the tracer. As a summary, $L_{e}$ is closely related to the wave disturbances enlarged by wave breaking events.

\section{Results and Discussions}

\subsection{Evaluation of Modeled Mixing Strength in the Stratosphere}

As explained in section $2 L_{e}$ calculated from the $\mathrm{R} 20$ truncated $\mathrm{CH}_{4}$ fields gives the strength of stirring processes which are resolvable under the R20 resolution. Large $L_{e}$ indicates that the $\mathrm{CH}_{4}$ contours on the isentropic surface are stretched and disturbed strongly. Figure 4 shows measured and modeled temporal evolutions of $L_{e}$ at 600 and $1100 \mathrm{~K}$ in both the Northern and Southern Hemispheres for the period 2009-2011. In the stratosphere one of the important dynamical structures is the surf zone, which 

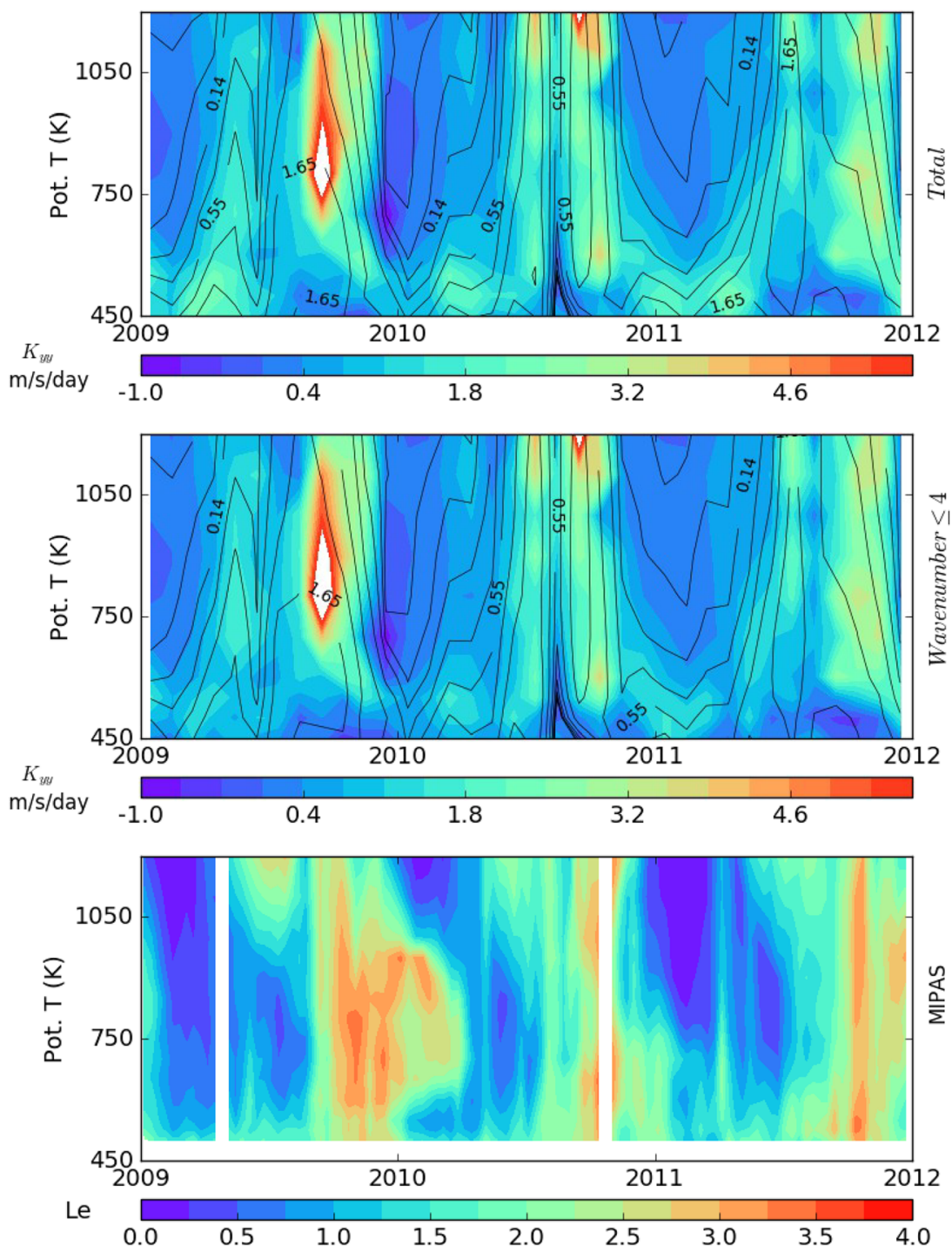

Figure 3. Temporal evolutions of the eddy diffusivity in Eulerian mean formulation $K_{y y}$ (colors) and the vertical component of the scaled E-P flux vector (black contours, in unit $\mathrm{m}^{2} / \mathrm{s}^{2}$ ) of total disturbances (top panel). Disturbances with wavenumber $\leq 4$ averaged over the latitudes $30-50^{\circ} \mathrm{S}$ (middle panel) and the temporal evolution of MIPAS measured $L_{e}$ averaged over the region $30-50^{\circ} \mathrm{S}$ (lower panel)

corresponds to the region with large $L_{e}$ in the extratropics. The extratropical $L_{e}$ shows seasonal cycles with maxima in the winter and minima in the summer. This seasonal variation is due to the seasonal cycle of the amount of the tropospheric wave propagating up into the stratosphere. Planetary waves can propagate upwards only in the westerlies and the zonal winds of the stratosphere change seasonally. The westerlies are dominant in the winter and easterlies in the summer (Andrews et al., 1987). During the transition from the westerlies to the easterlies the large $L_{e}$ region extends into the polar region due to strong disturbances associated with the breakup of the polar vortex (Allen \& Nakamura, 2001; Haynes \& Shuckburgh, 2000).

Compared to the measurements the model with the standard resolution $4^{\circ} \times 6^{\circ} \times 25$ underestimates stirring strength, especially in the extratropics. In the model the $L_{e}$ in the surf zone shows a smaller latitudinal coverage and a shorter temporal extent. Compared to Figure 2 the $L_{e}$ differences between the model and the measurements are larger than the differences in the different measured tracers. This result indicates that the $L_{e}$ differences between model and measurements result from model deficiencies. Since the equivalent length is 

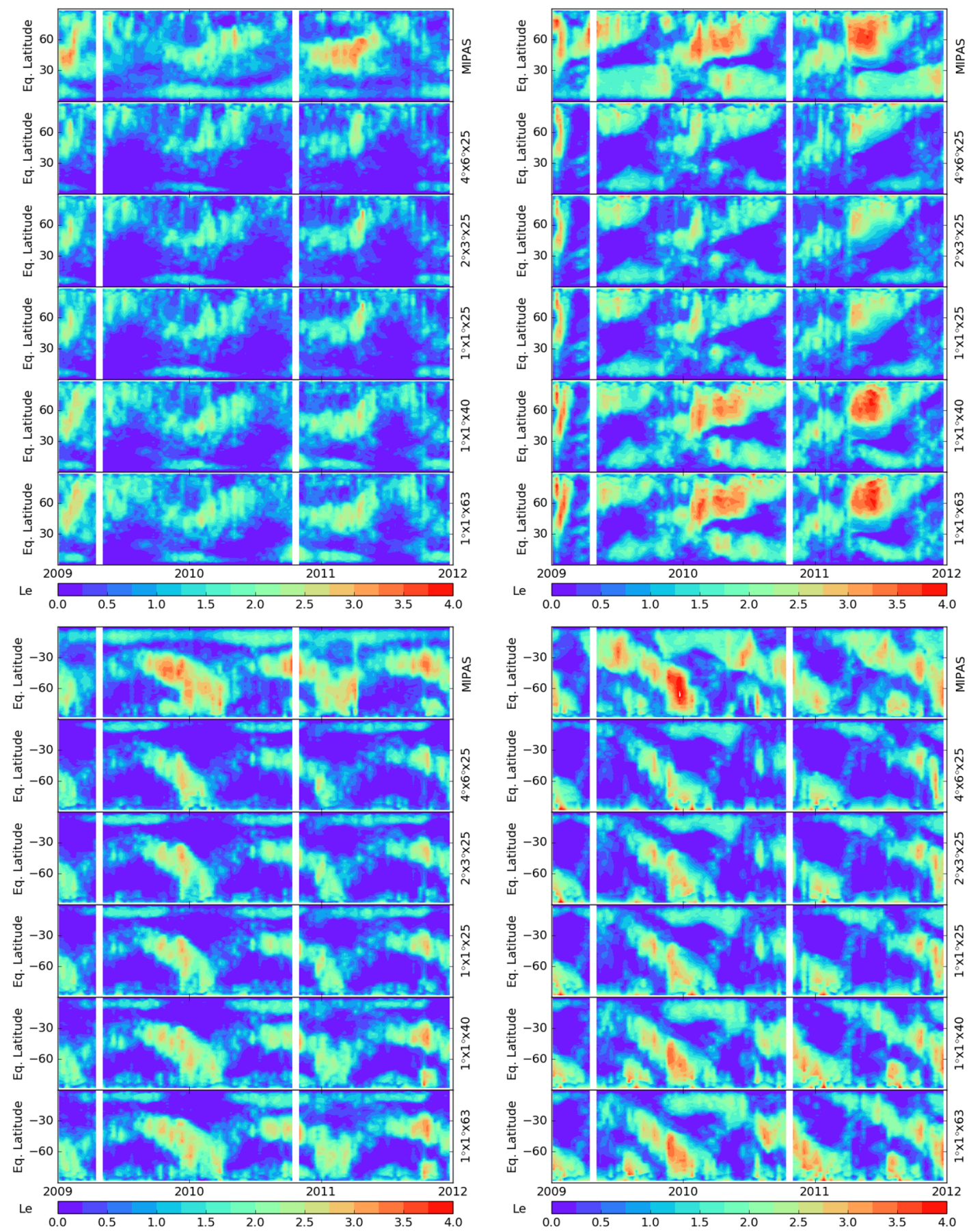

Figure 4. Temporal evolutions of $L_{e}$ at $600 \mathrm{~K}$ (left column) and $1100 \mathrm{~K}$ (right column) from the MIPAS measurements and TM5-4DVAR simulations with resolutions $4^{\circ} \times 6^{\circ} \times 25,2^{\circ} \times 3^{\circ} \times 25,1^{\circ} \times 1^{\circ} \times 25,1^{\circ} \times 1^{\circ} \times 40$, and $1^{\circ} \times 1^{\circ} \times 63$. The top panel shows results for the Northern Hemisphere and the lower panel for the Southern Hemisphere.

enlarged by wave disturbances and dissipated by the small-scale diffusion the differences between measurements and model output suggest that the deficiencies in the modeled $L_{e}$ should be attributed to dynamics and numerical diffusion of the transport scheme adopted by the model. The numerical diffusion mainly depends on the resolution of the model for a specific transport scheme. Figure 4 shows that increasing the horizontal resolution improves the representation for $L_{e}$ only to a minor extent. However, increasing the vertical layers from 25 to 40 at the same time results in a better agreement for $L_{e}$ between 
Table 2

Estimates of Isentropic and Diabatic Diffusivity, Globally Averaged $L_{e}^{2} / L_{0}^{2}$, and Effective Diffusivity $k_{e f f}$, the Pe Number Assuming a Eddy Speed of 10-100 $m / s$ and a Typical Eddy Size of 1,000 km for TM5-4DVAR and MIPAS Measurements

\begin{tabular}{lcccc}
\hline & $k_{h}\left(\mathrm{~m}^{2} / \mathrm{s}\right)$ & $k_{\ominus}\left(\mathrm{K}^{2} / \mathrm{s}\right)$ & $L_{e}^{2} / L_{0}^{2}$ & $k_{e f f}\left(\mathrm{~m}^{2} / \mathrm{s}\right)$ \\
\hline TM5-4DVAR $4^{\circ} \times 6^{\circ} \times 25$ & $19.72 \times 10^{5}$ & 0.0008 & 2.71 & $53.35 \times 10^{5}$ \\
TM5-4DVAR $2^{\circ} \times 3^{\circ} \times 25$ & $15.58 \times 10^{5}$ & 0.0007 & 2.87 & $44.68 \times 10^{5}$ \\
TM5-4DVAR $1^{\circ} \times 1^{\circ} \times 25$ & $17.11 \times 10^{5}$ & 0.0009 & 3.03 & $51.90 \times 10^{5}$ \\
TM5-4DVAR $1^{\circ} \times 1^{\circ} \times 40$ & $6.64 \times 10^{5}$ & 0.0002 & 3.94 & $6-64$ \\
TM5-4DVAR $1^{\circ} \times 1^{\circ} \times 63$ & $5.51 \times 10^{5}$ & 0.0001 & 4.20 & $26.19 \times 10^{5}$ \\
MIPAS with ERA-Interim diabatic heating rate & $1.48 \times 10^{5}$ & 0.0001 & 5.34 & $23.12 \times 10^{5}$ \\
MIPAS with MERRA-2 diabatic heating rate & $2.17 \times 10^{5}$ & 0.0003 & 5.34 & $18.90 \times 10^{5}$ \\
\hline
\end{tabular}

the model output and the measurements, especially in the northern hemisphere. The improvement is more significant at higher altitudes in both of the hemispheres.

For the small-scale diffusivity displayed in Table 2 the modeled isentropic diffusivity $k_{h}$ (5.51-19.72 $\left.\times 10^{5} \mathrm{~m}^{2} / \mathrm{s}\right)$ is higher than the measured one $\left(2.17 \times 10^{5} \mathrm{~m}^{2} / \mathrm{s}\right)$. As mentioned above, the modeled isentropic diffusivity results from small-scale dynamics with scales between the model and the R20 resolution, and the horizontal numerical diffusion. The modeled $k_{h}$ can be attributed to the horizontal numerical diffusion of the transport scheme and small-scale dynamics. The $k_{h}$ stays more or less the same for all the models with 25 vertical layers and decreases only when the number of the vertical layers is increased to 40. This result indicates that an improved horizontal resolution does not necessarily decrease the horizontal numerical diffusion proportionally when it is determined by the vertical diffusion set by the low vertical resolution of the model. According to Haynes and Anglade (1997), the combination of vertical shear and horizontal strain leads to a large number of thin, sloping structures in stratospheric tracer fields. These structures have a large aspect ratio (ratio of horizontal to vertical length scale) of about 250 in the lower stratosphere. Consequently, horizontal diffusivity is enhanced by an amount $k_{z} \alpha^{2}$ where $\alpha$ is the aspect ratio and $k_{z}$ is vertical diffusivity. The theory of Haynes and Anglade (1997) is consistent with the result we obtained; an increase of vertical resolution reduces horizontal numerical diffusion and the estimated isentropic diffusivity $k_{h}$. When the number of vertical layers is increased to 63 the vertical diffusivity decreases to half that of 40 vertical layers but the isentropic diffusivity changes only to a minor extent. This indicates that isentropic diffusivity is not dominated by vertical diffusion for models with at least 40 layers. The remaining higher isentropic diffusivity in the 40-layer model compared to that of the measurements can be attributed to horizontal numerical diffusion.

The magnitude of the equivalent length $L_{e}$ depends on the dynamics and the small-scale diffusivity. The dynamics applied in the model are created from the $1^{\circ} \times 1^{\circ} \times 60$ ERA-Interim data. With a very limited vertical resolution in the stratosphere in the model with only 25 vertical layers the 3 -D cascade of tracer variance is not adequately resolved. Severe truncation of tracer variance leads to biases in the modeled $L_{e}$. Impact of the small-scale diffusivity on $L_{e}$ can be explained with a theoretical argument according to Shuckburgh and Haynes (2003) and Marshall et al. (2006). The relationship between $L_{e}$ and $k_{h}$ depends on the relative magnitude of the advective time scale $(L / V)$ and the diffusive time scale $\left(L^{2} / k_{h}\right)$, summarized as the Peclet number $(\mathrm{Pe}) V L / k_{h}(V, L$ are typical scales for eddy speed and size). In the large Pe limit, the enhancement of the length of tracer contours by eddy disturbances dominates over the small-scale diffusion. In this case $k_{e f f}$ is independent of $k_{h}$ and $L_{e}^{2}$ is proportional to $1 / k_{h}$ (here $L_{e}^{2}$ refers to the original definition in Equation 2, not to the normalized one). The $k_{\text {eff }}$ scales like $k_{h}^{1 / 2}$ when Pe is small and approaches $k_{h}$ as Pe becomes even smaller. Consequently, $L_{e}^{2}$ scales like $1 / k_{h}^{1 / 2}$ and approaches $L_{0}^{2}$, respectively. Pe ranges about 10-100 if assuming an eddy speed of 10-100 m/s, a $k_{h}$ of $1.0 \times 10^{6} \mathrm{~m}^{2} / \mathrm{s}$ and a typical eddy size of $1,000 \mathrm{~km}$. For these values of $\mathrm{Pe} L_{e}^{2}$ scales like $k_{h}^{\alpha}$ with $-1 \% 3 \mathrm{C} \alpha \% 3 \mathrm{C}-0.5$ according to Marshall et al. (2006), so the equivalent length strongly depends on the magnitude of the small-scale diffusivity. The theoretical expectation is consistent with the results here; the models underestimate $L_{e}$ and overestimate $k_{h}$; the modeled $L_{e}$ increases significantly only when $k_{h}$ decreases significantly.

One of the uncertainties in the validation of the modeled isentropic diffusivity is that diabatic heating rates in the real atmosphere are unknown and have to be replaced with those from reanalysis datasets for the 

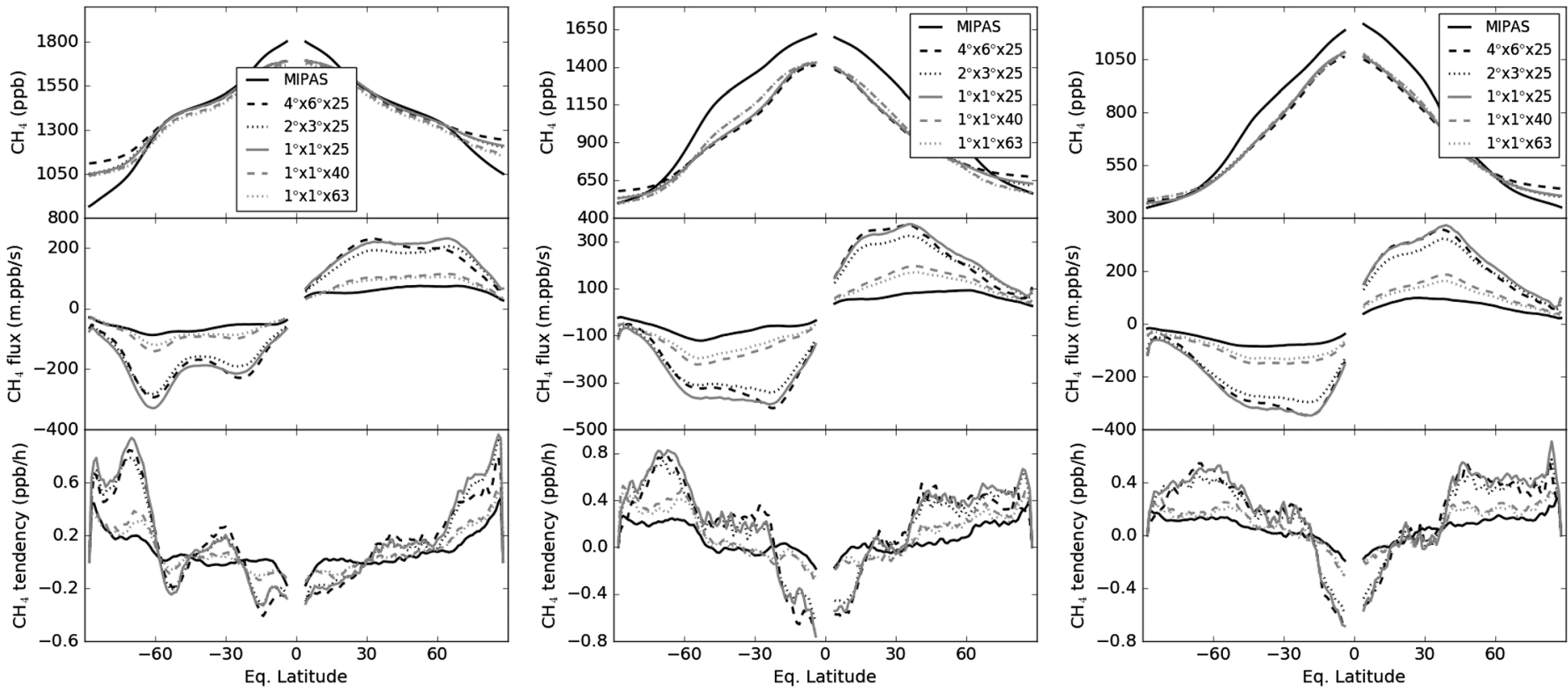

Figure 5. $\mathrm{CH}_{4}$ mixing ratios (the top panels), meridional fluxes of $\mathrm{CH}_{4}$ due to isentropic mixing processes $-k_{\text {eff }} \frac{\partial q_{\mathrm{CH}_{4}}}{r \partial \phi_{e}}$ (the middle panels), and the flux convergence $\frac{1}{\cos \phi_{e}} \frac{\partial}{r \partial \phi_{e}}\left(\cos \phi_{e} k_{\mathrm{eff}} \frac{\partial q_{C H_{4}}}{r \partial \phi_{e}}\right)$ (the lowermost panels) averaged over 2009-2011. The left, middle, and right columns show results on 500, 800, and $1100 \mathrm{~K}$ isentropic surfaces, respectively. Different lines indicate results for MIPAS (black solid), TM5-4DVAR with a resolution of $4^{\circ} \times 6^{\circ} \times 25$ (black dash), $2^{\circ} \times 3^{\circ} \times 25$ (black dotted line), $1^{\circ} \times 1^{\circ} \times 25$ (gray solid), $1^{\circ} \times 1^{\circ} \times 40$ (gray dash), and $1^{\circ} \times 1^{\circ} \times 63$ (gray dotted line)

derivation of $k_{h}$ from measurements. The diabatic heating contributes flows of tracer variance into the region bounded by 500 and $1200 \mathrm{~K}$ surfaces at the lower boundary $(500 \mathrm{~K})$ and out of the region at the upper boundary $(1200 \mathrm{~K})$ (see Equation 4). Because of the exponential decrease of air density with respect to altitude, the total contribution by the diabatic heating tends to increase the tracer variance in this region. As a result, $k_{h}$ derived from the measurements is underestimated if the residual circulation in the reanalysis data is too slow and overestimated if it is too fast.

\subsection{Estimation of $\mathrm{CH}_{4}$ Biases Due to Isentropic Mixing}

Figure 5 shows measured and TM5-4DVAR modeled $\mathrm{CH}_{4}$ mixing ratios, the meridional flux, and the flux convergence of $\mathrm{CH}_{4}$ due to isentropic mixing averaged over 2009-2011 at 500, 800, and $1100 \mathrm{~K}$. Compared to the MIPAS measurements the model underestimates $\mathrm{CH}_{4}$ mixing ratios in the tropics and overestimates them in the polar regions. The systematic underestimates of $\mathrm{CH}_{4}$ mixing ratios in the tropics by the models at 800 and $1100 \mathrm{~K}$ could be due to underestimates of vertical advection associated with the residual circulation. The poleward fluxes of $\mathrm{CH}_{4}$ due to isentropic mixing are higher in the model than in the measurements. The modeled excessive poleward fluxes transport tropical $\mathrm{CH}_{4}$ to high latitudes too fast. The flux convergence of $\mathrm{CH}_{4}$ from isentropic mixing is negative in the tropics and positive in the extratropics. One exception is around $60^{\circ} \mathrm{S}$ on the isentropic surface of $500 \mathrm{~K}$ surface where the modeled flux convergence derivative changes significantly from negative values to positive values. This anomaly can be explained with the polar transport barrier located there. The tropical side shows a large negative flux convergence due to a fast increase of tracer fluxes along latitudes and the polar side shows a large positive flux convergence due to a decrease of tracer fluxes. The models give more negative mixing-induced flux convergence in the tropics and more positive mixing-induced flux convergence in the extratropics. When the number of vertical layers is fixed to 25 , the magnitudes of these biases change to a minor extent for models with various horizontal resolutions $\left(4^{\circ} \times 6^{\circ}\right.$ to $\left.1^{\circ} \times 1^{\circ}\right)$. Significant reduction in the biases of the modeled fluxes and flux convergence is obtained by improving the vertical resolution.

For yearly averages the modeled temporal tendencies of $\mathrm{CH}_{4}$ mixing ratios due to isentropic mixing are similar to the measured ones as the number of vertical levels of the model increases from 25 to 40 as shown in 


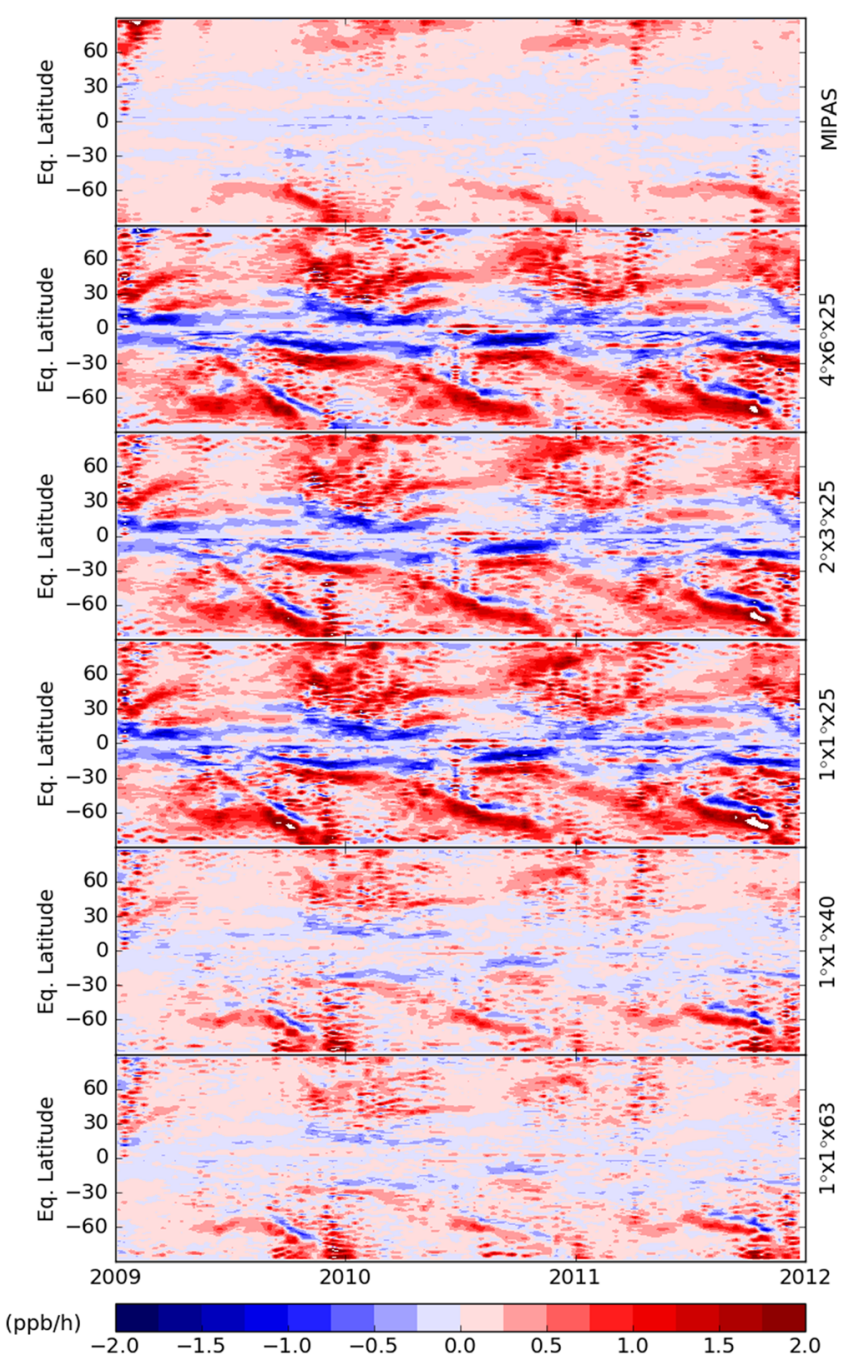

Figure 6. Temporal evolution of mixing-induced flux convergence of $\mathrm{CH}_{4}$ at $800 \mathrm{~K}$ in the measurement and models biases. The top panel gives the flux convergence for MIPAS and the following panels show the biases in the modeled flux convergence under the resolutions $4^{\circ} \times 6^{\circ} \times 25,2^{\circ} \times 3^{\circ} \times 25,1^{\circ} \times 1^{\circ} \times 25$, $1^{\circ} \times 1^{\circ} \times 40$, and $1^{\circ} \times 1^{\circ} \times 63$.
Figure 5. However, isentropic mixing is closely related to wave activities that present seasonal variations. The winter hemisphere is disturbed strongly by wave activities but the summer hemisphere is calm. Correspondingly, isentropic mixing is stronger in the winter hemisphere than in the summer hemisphere. To see the seasonal variation of the model errors, Figure 6 shows the evolution of the flux convergence derived from the measurements and the model biases in the flux convergence at $800 \mathrm{~K}$ for a period of 3 years. It is clear that the flux convergence is significant in the winter only in the northern extratropics. For the model with a resolution of $1^{\circ} \times 1^{\circ} \times 40$ biases in the flux convergence are as large as $0.5 \mathrm{ppb} / \mathrm{hr}$ compared to about $0.2 \mathrm{ppb} / \mathrm{hr}$ for the yearly averages in Figure 5. This difference is important since the time series of measurements is an input to inverse models.

Isentropic mixing enhances $\mathrm{CH}_{4}$ mixing ratios in the extratropics and diabatic sinking moves the added $\mathrm{CH}_{4}$ downward into the troposphere. The diabatic sinking is slow compared to the isentropic mixing. Accordingly, accumulation of model biases due to isentropic mixing can take place only on a short time scale, that is, a few days. Assuming isentropic mixing is dominant over the vertical transport on a time scale of 3 days and model biases in the flux convergence of $\mathrm{CH}_{4}$ are $0.5-1.0 \mathrm{ppb} / \mathrm{hr}$ for the model of $4^{\circ} \times 6^{\circ} \times 25$ (and $\left.2^{\circ} \times 3^{\circ} \times 25,1^{\circ} \times 1^{\circ} \times 25\right)$ and $0.2-0.5 \mathrm{ppb} / \mathrm{hr}$ for the model of $1^{\circ} \times 1^{\circ} \times 40$ in the extratropical stratosphere. The corresponding biases in the total column-averaged mixing ratio of $\mathrm{CH}_{4}$ are 7-14 and 3-7 ppb, respectively, assuming that the stratosphere takes one fifth of the mass of the atmosphere. These biases in the total column-averaged mixing ratio are important for an inverse model that infers $\mathrm{CH}_{4}$ emissions from measurements of total column-averaged $\mathrm{CH}_{4}$ mixing ratio. For example, latitudinal/monthly bias correction of a few tens of ppb is derived during inverse modeling of global $\mathrm{CH}_{4}$ emissions using SCIAMACHY satellite retrievals (Bergamaschi et al., 2009). The diagnosed deficiencies in the atmospheric transport scheme of TM5-4DVAR can lead to substantial biases in the retrieved trace gas emissions. We estimate emission biases by assuming that biases in the column-integrated flux convergence need to be compensated by surface emissions. The biases in the modeled flux convergence can then be translated to biases in inverted $\mathrm{CH}_{4}$ emissions by the factor $(1 / 5) \cdot(16 / 29) \cdot\left(10^{5} / 9.8\right) \cdot\left(10^{-9}\right) \cdot\left(10^{6}\right)$ in the extratropics. The factor transforms the stratospheric flux convergence in $\mathrm{ppb} / \mathrm{h}$ to surface emissions in $\mathrm{mg} / \mathrm{m}^{2} / \mathrm{hr}$. In this factor, $1 / 5$ is the approximate mass fraction of the stratosphere in the extratropics, $16 / 29$ is ratio of molecular mass of $\mathrm{CH}_{4}$ and air, $10^{5} \mathrm{~Pa}$ is surface pressure, $9.8 \mathrm{~m} / \mathrm{s}^{2}$ is the gravitational constant, $10^{-9}$ is $\mathrm{ppb}$, and $10^{6}$ transform coefficient from $\mathrm{kg}$ to $\mathrm{mg}$. Estimated biases in the surface emission are $0.5-1 \mathrm{mg} / \mathrm{m}^{2} / \mathrm{hr}$ for the model of $4^{\circ} \times 6^{\circ} \times 25$ (and $\left.2^{\circ} \times 3^{\circ} \times 25,1^{\circ} \times 1^{\circ} \times 25\right)$ and $0.2-0.5 \mathrm{mg} / \mathrm{m}^{2} / \mathrm{hr}$ for the model of $1^{\circ} \times 1^{\circ} \times 40$ in the extratropics. The estimated biases in $\mathrm{CH}_{4}$ surface emissions are large compared to $\mathrm{CH}_{4}$ emission rates of $0-2 \mathrm{mg} / \mathrm{m}^{2} / \mathrm{hr}$ in the northern extratropics and those below $0.4 \mathrm{mg} / \mathrm{m}^{2} / \mathrm{hr}$ in the southern extratropics (Bergamaschi et al., 2009). In the above estimations we assume a vertically uniform sampling weight for satellite measurements. For SCIAMACHY and GOSAT the sampling weights are larger in the troposphere than in the stratosphere. In addition, the inverse model estimates surface emissions based on measurements while taking a priori emissions into account. It means that only part of the information in the inverted emissions is based on measurements. The fraction of the information from measurements depends on measurement noise and the a priori information used by the inverse model. When taking sampling weights and a priori emissions into account the estimated biases in the surface emissions will decrease. 


\section{Conclusions}

In this work the TM5-4DVAR, an inverse model for $\mathrm{CH}_{4}$, is evaluated against MIPAS and MLS in terms of mixing properties in the stratosphere. For our studies we used only the forward part of the model. The modified Lagrangian-mean formalism is used as the analysis framework. As a result, the mixing processes are separated into large-scale stirring measured by the equivalent length $L_{e}$ and small-scale diffusion measured by the isentropic diffusivity $k_{h}$. A spherical harmonics expansion with the R20 truncation is applied to extract the large-scale information from the measurements and the model outputs.

Comparisons of the measured $L_{e}$ to the simulations reveal that MIPAS and MLS measured $\mathrm{CH}_{4}$ and $\mathrm{N}_{2} \mathrm{O}$ give similar $L_{e}$. Generally, the model underestimates $L_{e}$ and overestimates $k_{h}$ compared to the measurements. The magnitude of the bias in the modeled mixing parameters depends on the model resolution. Compared to the model with the frequently applied coarse resolution $4^{\circ} \times 6^{\circ} \times 25$ (latitude $\times$ longitude $\times$ vertical layers) improving the horizontal resolution alone does not reduce the model biases in the $L_{e}$ and the $k_{h}$. When both, the horizontal and vertical resolutions are increased, the bias in the modeled $k_{h}$ decreases from tenfold to threefold. The bias on the modeled $L_{e}$ decreases significantly associated with the reduced $k_{h}$. It is argued that the reduction of the bias in the modeled $k_{h}$ is due to reduced numerical diffusion in the vertical component of the applied transport scheme.

With these derived mixing parameters at hand, isentropic mixing-induced meridional fluxes and the flux convergence of $\mathrm{CH}_{4}$ are estimated for both the measurements and the models. It is revealed that the TM5-4DVAR simulates an excessive poleward flux and, consequently, too negative flux convergence in the tropics and too positive one in the extratropics. For TM5-4DVAR with resolutions of $4^{\circ} \times 6^{\circ} \times 25$, $2^{\circ} \times 3^{\circ} \times 25$ and $1^{\circ} \times 1^{\circ} \times 25$ (latitude $\times$ longitude $\times$ vertical layers) the biases do not reduce substantially. For TM5-4DVAR with resolution of $1^{\circ} \times 1^{\circ} \times 40$ (additional vertical layers locate within the stratosphere and the vertical resolution is the same as in ERA-Interim there) the biases reduce globally. A further increase of the vertical model resolution in the stratosphere does not further reduce the biases. Biases in $\mathrm{CH}_{4}$ surface emissions caused by the unrealistic isentropic mixing in the model are estimated to be $0.5-1 \mathrm{mg} / \mathrm{m}^{2} / \mathrm{hr}$ for the model of $4^{\circ} \times 6^{\circ} \times 25$ (and $2^{\circ} \times 3^{\circ} \times 25,1^{\circ} \times 1^{\circ} \times 25$ ) and $0.2-0.5 \mathrm{mg} / \mathrm{m}^{2} / \mathrm{hr}$ for the model of $1^{\circ} \times 1^{\circ} \times 40$ in the extratropics.

For upcoming versions of the transport model, we recommend to improve the parameterization of small-scale diffusion in the stratosphere and to take steps toward reducing numerical diffusion.

\section{Appendix A: Derivation of the Tracer Variance Equation}

The tracer variance equation (Equation 4) is derived here. Starting from the advection-diffusion equation for the mixing ratio $q$ of some trace gas, that is,

$$
\frac{\partial \sigma q}{\partial t}+\nabla \cdot(\sigma q \vec{v}-\sigma K \nabla q)=-\sigma \frac{q}{\tau_{\text {chem }}} .
$$

Note that $K$ includes isentropic diffusivity and diabatic diffusivity. The $\tau_{\text {chem }}$ is lifetime of the trace gas due to the chemical oxidation. Multiplying the equation by $q$ gives

$$
q \frac{\partial \sigma q}{\partial t}+q \nabla \cdot(\sigma q \vec{v})=q \nabla \cdot(\sigma K \nabla q)-\sigma \frac{q^{2}}{\tau_{\text {chem }}} .
$$

Rearranging each term in Equation A2, that is,

$$
\begin{aligned}
& q \frac{\partial \sigma q}{\partial t}=\frac{1}{2} \frac{\partial \sigma q^{2}}{\partial t}+\frac{1}{2} q^{2} \frac{\partial \sigma}{\partial t} \\
& q \nabla \cdot(\sigma q \vec{v})=q^{2} \nabla \cdot(\sigma \vec{v})+\frac{1}{2} \sigma \vec{v} \cdot \nabla q^{2}=\frac{1}{2} q^{2} \nabla \cdot(\sigma \vec{v})+\frac{1}{2} \nabla \cdot\left(\sigma q^{2} \vec{v}\right) \\
& q \nabla(\sigma K \nabla q)=\nabla(\sigma q K \nabla q)-(\sigma K \nabla q) \nabla q=\frac{1}{2} \nabla\left(\sigma K \nabla q^{2}\right)-\sigma k_{h}\left|\nabla_{h} q\right|^{2}-\sigma k_{\theta}\left(\frac{\partial q}{\partial \theta}\right)^{2},
\end{aligned}
$$

with this rearrangement Equation A2 can transformed to 


$$
\frac{1}{2} \frac{\partial \sigma q^{2}}{\partial t}+\frac{1}{2} q^{2}\left(\frac{\partial \sigma}{\partial t}+\nabla(\sigma \vec{v})\right)+\frac{1}{2} \nabla\left(\sigma q^{2} \vec{v}\right)=\frac{1}{2} \nabla\left(\sigma K \nabla q^{2}\right)-\sigma k_{h}\left|\nabla_{h} q\right|^{2}-\sigma k_{\theta}\left(\frac{\partial q}{\partial \theta}\right)^{2}-\sigma \frac{q^{2}}{\tau_{\text {chem }}}
$$

Integrating over the stratospheric region between the isentropic layers 500 and $1200 \mathrm{~K}$ and using the divergence theorem and by denoting the air mass weighted mean by an overbar gives

$$
\frac{1}{2} \frac{d \overline{q^{2}}}{d t}=-\frac{1}{2 M} \int_{S} \sigma q^{2} \vec{v} \cdot \vec{n} d S+\frac{1}{2 M} \int_{S} \sigma\left(K \nabla q^{2}\right) \cdot \vec{n} d S-k_{h}^{*} \overline{\left|\nabla_{h} q\right|^{2}}-k_{\theta}^{*} \overline{\left(\frac{\partial q}{\partial \theta}\right)^{2}}-\frac{\overline{q^{2}}}{\tau_{\text {chem }}^{*}}
$$

where $S$ denotes the boundary and $\vec{n}$ the outward pointing normal of $S$. In Equation A3 the diffusion coefficients and chemical lifetime are averages in following ways

$$
k_{h}^{*}=\frac{\overline{k_{h}\left|\nabla_{h} q\right|^{2}}}{\overline{\left|\nabla_{h} q\right|^{2}}}, \quad k_{h}^{*}=\frac{\overline{k_{h}\left|\nabla_{h} q\right|^{2}}}{\overline{\left|\nabla_{h} q\right|^{2}}}, \quad \frac{1}{\tau_{\text {chem }}^{*}}=\frac{\overline{q^{2} / \tau_{\text {chem }}}}{\overline{q^{2}}}
$$

over the volume weighted by air mass and square of the gradient of the tracer mixing ratio. Temporal variation of $M$ compared to that of $q^{2}$ is overlooked in arriving at Equation A3. Recognizing that $S$ is just the lower and the upper bounding isentrope gives the final result (cp. Equation 4).

\section{Data Availability Statement}

The MIPAS data are operational V7 data processed by ESA, which is publicly available at https://earth.esa. int/web/guest/data-access/view-data-product/-/article/mipas-atmospheric-pressure-temperature-data-constituents-profiles-1547 with registration. The MLS data are available at https://acdisc.gesdisc.eosdis.nasa. gov/data/Aura_MLS_Level2/ website. ERA-Interim described in Dee et al. (2011, doi: 10.1002/qj.828) and MERRA-2 in Gelaro et al. (2017, doi: 10.1175/JCLI-D-16-0758.1) are publicly available. The model TM5-4DVAR is v1.4 and available online (https://sourceforge.net/projects/tm5/).

\section{Acknowledgments}

The research is funded by the Project 41805030 supported by NSFC. We acknowledge funding from the EU project InGOS and the Fundamental Research Funds for the Central Universities lzujbky-2018-5. We gratefully acknowledge the constructive comments by both anonymous reviewers, which helped to improve the manuscript. We thank Peter Bergamaschi at European Commission Joint Research Centre for his helpful advices. Thanks are paid for Segers, A. J. for the helps in running TM5-4DVAR as well.

\section{References}

Abalos, M., Randel, W. J., \& Birner, T. (2016). Phase-speed spectra of eddy tracer fluxes linked to isentropic stirring and mixing in the upper troposphere and lower stratosphere. Journal of the Atmospheric Sciences, 73(12), 4711-4730. https://doi.org/10.1175/JAS-D-16-0167.1

Abernathy, R., Marshall, J., Mazloff, M., \& Shuckburgh, E. (2010). Enhancement of mesoscale eddy stirring at steering levels in the Southern Ocean. Journal of Physical Oceanography, 40(1), 170-184. https://doi.org/10.1175/2009JPO4201.1

Allen, D. R., \& Nakamura, N. (2001). A seasonal climatology of effective diffusivity in the stratopshere. Journal of Geophysical Research, 106(D8), 7917-7935. https://doi.org/10.1029/2000JD900717

Andrews, D. G., Holton, J. R., \& Leovy, C. B. (1987). Middle atmospheric dynamics, International Geophysics Series (Vol. 40, p. 489). New York: Academic Press.

Bergamaschi, P., Corazza, M., Karstens, U., Athanassiadou, M., Thompson, R. L., Pison, I., et al. (2015). Top-down estimates of European $\mathrm{CH}_{4}$ and $\mathrm{N}_{2} \mathrm{O}$ emissions based on four different inverse models, Atmospheric Chemistry and Physics, 15, 715-736, https://doi.org/ 10.5194/acp-15-715-2015

Bergamaschi, P., Franenberg, C., Meirink, J. F., Krol, M., Villani, M. G., Houweling, S., et al. (2009). Inverse modeling of global and regional $\mathrm{CH}_{4}$ emissions using SCIAMACHY satellite retrievals. Journal of Geophysical Research, 114, D22301. https://doi.org/10.1029/ 2009JD012287

Bergamaschi, P., Houweling, S., Segers, A., Krol, M., Frankenberg, C., Scheepmaker, R. A., et al. (2013). Atmospheric $\mathrm{CH}_{4}$ in the first decade of the $21^{\text {st }}$ century: Inverse modeling analysis using SCIAMACHY satellite retrievals and NOAA surface measurements. Journal of Geophysical Research: Atmospheres, 118, 7350-7369. https://doi.org/10.1002/jgrd.50480

Bovensmann, H., Burrows, J. P., Buchwitz, M., Frerick, J., Noël, S., Rozanov, V. V., et al. (1999). SCIAMACHY—Mission objectives and measurement modes. Journal of the Atmospheric Sciences, 56(2), 127-150. https://doi.org/10.1175/1520-0469(1999)056\%3C0127: SMOAMM\%3E2.0.CO;2

Chen, P. (1994). The permeability of the Antarctic vortex edge. Journal of Geophysical Research, 99(D10), 20563. https://doi.org/10.1029/ 94JD01754

Chen, P., Holton, J. R., O'neill, A., \& Swinbank, R. (1994a). Isentropic mass exchange between the tropics and extratropics in the stratosphere. Journal of the Atmospheric Sciences, 51(20), 3006-3018. https://doi.org/10.1175/1520-0469(1994)051\%3C3006:IMEBTT\%3E2.0. $\mathrm{CO} ; 2$

Chen, P., Holton, J. R., O'neill, A., \& Swinbank, R. (1994b). Quasi-horizontal transport and mixing in the Antarctic stratosphere. Journal of Geophysical Research, 99(D8), 16851. https://doi.org/10.1029/94JD00784

Crevoisier, C., Nobileau, D., Armante, R., Crépeau, L., Machida, T., Sawa, Y., et al. (2013). The 2007-2011 evolution of tropical methane in the mid-troposphere as seen from space by MetOp-A/IASI. Atmospheric Chemistry and Physics, 13(8), 4279-4289. https://doi.org/ 10.5194/acp-13-4279-2013

Daley, R., \& Bourassa, Y. (1978). Rhomboidal versus triangular spherical harmonic truncation: Some verification statistics. AtmosphereOcean, 16(2), 187-196. https://doi.org/10.1080/07055900.1978.9649026 
Dee, D. P., Uppala, S. M., Simmons, A. J., Berrisford, P., Poli, P., Kobayashi, S., et al. (2011). The ERA-Interim reanalysis: Configuration and performance of the data assimilation system. Quarterly Journal of the Royal Meteorological Society, 137(656), 553-597. https://doi.org/ $10.1002 /$ qj. 828

Edmon, H. J., Hoskins, B. J., \& McIntyre, M. E. (1980). Eliassen-Palm cross sections for the troposphere. Journal of the Atmospheric Sciences, 37(12), 2600-2616. https://doi.org/10.1175/1520-0469(1980)037\%3C2600:EPCSFT\%3E2.0.CO;2

Fischer, H., Birk, M., Blom, C., Carli, B., Carlotti, M., von Clarmann, T., et al. (2008). MIPAS: An instrument for atmospheric and climate research. Atmospheric Chemistry and Physics, 8(8), 2151-2188. https://doi.org/10.5194/acp-8-2151-2008

Gelaro, R., McCarty, W., Suárez, M. J., Todling, R., Molod, A., Takacs, L., et al. (2017). The modern-era retrospective analysis for research and applications, version 2 (MERRA-2). Journal of Climate, 30(14), 5419-5454. https://doi.org/10.1175/jcli-d-16-0758.1

Haynes, P. (2004). Transport and mixing in the atmosphere, proceedings of 21st ICTAM congress. Berlin, Germany: Kluwer Academic Publishers, August 15-21.

Haynes, P., \& Anglade, L. (1997). The vertical-scale cascade in atmospheric tracers due to large-scale differential advection. Journal of the Atmospheric Sciences, 54(9), 1121-1136. https://doi.org/10.1175/1520-0469(1997)054\%3C1121:TVSCIA\%3E2.0.CO;2

Haynes, P., \& Shuckburgh, E. (2000). Effective diffusivity as a diagnostic of atmospheric transport: 1. Stratosphere. Journal of Geophysical Research, 105(D18), 22,777-22,794. https://doi.org/10.1029/2000JD900093

Holton, J. R. (2004). An introduction to dynamic meteorology, fourth edition, International Geophysics Series (Vol. 88). New York: Elsevier Academic Press.

Hoppe, C. M., Hoffmann, L., Konopka, P., Grooß, J.-U., Ploeger, F., Günther, G., et al. (2014). The implementation of the CLaMS Lagrangian transport core into the chemistry climate model EMAC 2.40.1: Application on age of air and transport of long-lived trace species. Geoscientific Model Development, 7(6), 2639-2651. https://doi.org/10.5194/gmd-7-2639-2014

Joeckel, P., Tost, H., Pozzer, A., Brühl, C., Buchholz, J., Ganzeveld, L., et al. (2006). The atmospheric chemistry general circulationmodel ECHAM5/MESSy1: Consistent simulation of ozone from the surface to the mesosphere. Atmospheric Chemistry and Physics, 6(12), 5067-5104. https://doi.org/10.5194/acp-6-5067-2006

Kalicinsky, C., Grooß, J.-U., Günther, G., Ungermann, J., Blank, J., Höfer, S., et al. (2013). Observations of filamentary structures near the vortex edge in the Arctic winter lower stratosphere. Atmospheric Chemistry and Physics, 13(21), 10,859-10,871. https://doi.org/10.5194/ acp-13-10859-2013

Khosrawi, F., Grooß, J.-U., Müller, R., Konopka, P., Kouker, W., Ruhnke, R., et al. (2005). Intercomparison between Lagrangian and Eulerian simulations of the development of mid-latitude streamers as observed by CRISTA. Atmospheric Chemistry and Physics, 5(1), 85-95. https://doi.org/10.5194/acp-5-85-2005

Krol, M., Houweling, S., Bregman, B., van den Broek, M., Segers, A., van Velthoven, P., et al. (2005). The two-way nested global chemistry-transport zoom model TM5: Algorithm and applications. Atmospheric Chemistry and Physics, 5(2), 417-432. https://doi.org/ 10.5194/acp-5-417-2005

Kuze, A., Suto, H., Shiomi, K., Kawakami, S., Tanaka, M., Ueda, Y., et al. (2016). Update on GOSAT TANSOFTS performance, operations, and data products after more than 6 years in space. Atmospheric Measurement Techniques, 9(6), 2445-2461. https://doi.org/10.5194/amt9-2445-2016

Leibensperger, E. M., \& Plumb, R. A. (2014). Effective diffusivity in baroclinic flow. Journal of the Atmospheric Sciences, 71(3), 972-984. https://doi.org/10.1175/JAS-D-13-0217.1

Locatelli, R., Bousquet, P., Saunois, M., Chevallier, F., \& Cressot, C. (2015). Sensitivity of the recent methane budget to LMDz sub-grid-scale physical parameterizations. Atmospheric Chemistry and Physics, 15, 9765-9780. https://doi.org/10.5194/acp-15-9765-2015

Marshall, J., Shuckburgh, E., Jones, H., \& Hill, C. (2006). Estimates and implications of surface eddy diffusivity in the Southern Ocean derived from tracer transport. Journal of Physical Oceanography, 36(9), 1806-1821. https://doi.org/10.1175/JPO2949.1

Mcintyre, M. E., \& Palmer, T. N. (1983). Breaking planetary waves in the stratosphere. Nature, 305(5935), 593-600. https://doi.org/10.1038/ $305593 \mathrm{a} 0$

Meirink, J. F., Bergamaschi, P., \& Krol, M. C. (2008). Four-dimensional variational data assimilation for inverse modelling of atmospheric methane emissions: Method and comparison with synthesis inversion. Atmospheric Chemistry and Physics, 8(21), 6341-6353. https://doi. org/10.5194/acp-8-6341-2008

Nakamura, N. (1996). Two-dimensional mixing, edge formation, and permeability diagnosed in an area coordinate. Journal of the Atmospheric Sciences, 53(11), 1524-1537. https://doi.org/10.1175/1520-0469(1996)053\%3C1524:TDMEFA\%3E2.0.CO;2

Nakamura, N., \& Ma, J. (1997). Modified Lagrangian-mean diagnostics of the stratospheric polar vortices: 2 . Nitrous oxide and seasonal barrier migration in the cryogenic limb array etalon spectrometer and SKYHI general circulation model. Journal of Geophysical Research, 102(D22), 25,721-25,735.

Neu, J. L. (2003). Variability of the subtropical “edges” in the stratosphere. Journal of Geophysical Research, 108(D15), 4482. https://doi.org/ 10.1029/2002JD002706

Palmer, T. N. (1982). Properties of the Eliassen-Palm flux for planetary scale motions. Journal of the Atmospheric Sciences, 39, 992-997.

Payne, V. H., Clough, S. A., Shephard, M. W., Nassar, R., \& Logan, J. A. (2009). Information-centered representation of retrievals with limited degrees of freedom for signal: Application to methane from the Tropospheric Emission Spectrometer. Journal of Geophysical Research, 114, D10307. https://doi.org/10.1029/2008JD010155

Pison, I., Ringeval, B., Bousquet, P., Prigent, C., \& Papa, F. (2013). Stable atmospheric methane in the 2000s: Key-role of emissions from natural wetlands. Atmospheric Chemistry and Physics, 13(23), 11,609-11,623. https://doi.org/10.5194/acp-13-11609-2013

Pommrich, R., Müller, R., Grooß, J.-U., Konopka, P., Ploeger, F., Vogel, B., et al. (2014). Tropical troposphere to stratosphere transport of carbon monoxide and long-lived trace species in the Chemical Lagrangian Model of the Stratosphere (CLaMS). Geoscientific Model Development, 7, 2895-2916. https://doi.org/10.5194/gmd-7-2895-2014

Randel, W. J., Gille, J. C., Roche, A. E., Kumer, J. B., Mergenthaler, J. L., Waters, J. W., et al. (1993). Stratospheric transport from the tropics to middle latitudes by planetary-wave mixing. Nature, 365(6446), 533-535. https://doi.org/10.1038/365533a0

Sheese, P., Walker, K., Boone, C., Bernath, P., Froidevaux, L., Funke, B., et al. (2017). ACE-FTS ozone, water vapour, nitrous oxide, nitric acid, and carbon monoxide profile comparisons with MIPAS and MLS. Journal of Quantitative Spectroscopy and Radiative Transfer, 186 , 63-80. https://doi.org/10.1016/j.jqsrt.2016.06.026

Shuckburgh, E., \& Haynes, P. (2003). Diagnosing transport and mixing using a tracer-based coordinate system. Physics of Fluids, 15(11), 3342-3357. https://doi.org/10.1063/1.1610471 
Spivakovsky, C. M., Logan, J. A., Montzka, S. A., Balkanski, Y. J., Foreman-Fowler, M., Jones, D. B. A., et al. (2000). Three-dimensional climatological distribution of tropospheric OH: Update and evaluation. Journal of Geophysical Research, 105(D7), 8931-8980. https:// doi.org/10.1029/1999JD901006

Steinhorst, H.-M., Konopka, P., Günther, G., \& Müller, R. (2005). How permeable is the edge of the Arctic vortex: Model studies of winter 1999-2000. Journal of Geophysical Research, 110, D06105. https://doi.org/10.1029/2004JD005268

Stenke, A., Dameris, M., Grewe, V., \& Garny, H. (2009). Implications of Lagrangian transport for simulations with a coupled chemistry-climate model. Atmospheric Chemistry and Physics, 9(15), 5489-5504. https://doi.org/10.5194/acp-9-5489-2009

Trepte, C. R., \& Hitchman, M. H. (1992). Tropical stratospheric circulation deduced from satellite aerosol data. Nature, 355(6361), 626-628. https://doi.org/10.1038/355626a0

Wetzel, G., Höpfner, M., \& Oelhaf, H. (2016). Long-term validation of MIPAS ESA operational products using MIPAS-B measurements, ESA Technical Note.

Worden, J. R., Turner, A. J., Bloom, A., Kulawik, S. S., Liu, J., Lee, M., et al. (2015). Quantifying lower tropospheric methane concentrations using GOSAT near-IR and TES thermal IR measurements. Atmospheric Measurement Techniques, 8(8), 3433-3445. https://doi.org/ 10.5194/amt-8-3433-2015

Xiong, X., Barnet, C., Maddy, E. S., Gambacorta, A., King, T. S., \& Wofsy, S. C. (2013). Mid-upper tropospheric methane retrieval from IASI and its validation. Atmospheric Measurement Techniques, 6(9), 2255-2265. https://doi.org/10.5194/amt-6-2255-2013 